\title{
Legitimate Policymaking: The Importance of Including Health-care Workers in Limit-Setting Decisions in Health care
}

\author{
Ann-Charlotte Nedlund and Kristine Bærøe
}

\section{Linköping University Post Print}

\section{Tweet}

N.B.: When citing this work, cite the original article.

Original Publication:

Ann-Charlotte Nedlund and Kristine Bærøe, Legitimate Policymaking: The Importance of Including Health-care Workers in Limit-Setting Decisions in Health care, 2014, Public Health Ethics, (7), 2, 123-133. http://dx.doi.org/10.1093/phe/phu016 Copyright: Oxford University Press (OUP): Policy F - Oxford Open Option D http://www.oxfordjournals.org/

Postprint available at: Linköping University Electronic Press http://urn.kb.se/resolve?urn=urn:nbn:se:liu:diva-107915 


\title{
Legitimate Policymaking: The Importance of Including Health-care Workers in Limit-Setting Decisions in Health Care
}

\author{
Ann-Charlotte Nedlund*, National Centre for Setting Priorities in Health Care, \\ Department of Medical and Health Sciences, Linköping University, Sweden \\ Kristine Bærøe, Department of Global Public Health and Primary Care, \\ University of Bergen, Norway \\ *Corresponding author: Ann-Charlotte Nedlund, National Centre for Setting Priorities in Health Care, Department of Medical and Health Sciences, \\ Linköping University, SE-581 83 Linköping, Sweden. Tel.: +46 10 1034448; Fax: +46 13 149403; Email: ann-charlotte.nedlund@liu.se
}

The concept of legitimacy is often used and emphasized in the context of setting limits in health care, but rarely described is what is actually meant by its use. Moreover, it is seldom explicitly stated how health-care workers can contribute to the matter, nor what weight should be apportioned to their viewpoints. Instead the discussion has focused on whether they should take on the role of the patients' advocate or that of gatekeeper to the society's resources. In this article, we shed light on the role of health-care workers in limit setting and how their conferred legitimacy may support subordinators' (i.e. citizens') conferred legitimacy. We argue that health-care workers have an important role to play as both moral and political agents in limit setting, and delineate normative conditions that justify and facilitate health-care workers in conferring legitimacy on this kind of decision. Their role and potential impact on political limit setting does not-theoretically-affect the idea of democratic legitimacy negatively. Rather, as we suggest, by designing for limit-setting policymaking accordingly, healthcare workers, as well as citizens, are more justified in conferring democratic legitimacy to health-care limitsetting decisions than if these concerns were not addressed.

\section{Introduction}

The role of health-care workers in limit-setting decision-making in publicly funded health care, has basically centred on whether they should take on the role of the patients' advocate or that of gatekeeper to the society's resources (Weinstein, 2001; Schwartz, 2002; Carlsen and Norheim, 2005; Daniels and Sabin, 2008). In discussions on democratic participation in rationing processes, health-care workers are usually recognized as stakeholders and expected to participate. However, it is rarely explicitly stated how exactly their contribution matters to democratic deliberation, nor what weight should be apportioned to their viewpoints. Also, when health-care workers' perceptions on the legitimacy of allocation decisions are in fact considered important, they seem to realize nothing more than an instrumental value; with health-care workers contesting the decisions, the decisions might simply not be carried out (Peacock et al., 2009). In this article, we will argue that health-care workers should be considered as moral and political agents in limit-setting decisions in publicly funded health care, and that designing for decision-making processes that promote their positive judgments on the legitimacy of these decisions, is of substantive importance. In fact, as we will point out, considering health-care workers as essentially serving the interests of others, be it patients or society, is likely to undermine basic values of democracy or at least contradict bearing principles of political deliberative theories.

The crucial issue of distribution of public goods framed by Lasswell (1958) - 'who gets what, when and how'-relates to the exercise of political power to which citizens have given democratic legitimacy. Moreover, legitimacy is important since it is a key to stability. To ensure legitimacy of limit setting in health care seems extremely important. Denial of potentially beneficial care has a huge impact on people's lives, and basing such decisions on poorly designed processes for reaching well-justified conclusions, is likely to activate 
involvement of other decision-making bodies, such as courts. Aiming to strengthen the legitimacy of the limit-setting decisions carried out within health-careproviding institutions themselves, occurs as a more effective and sustainable strategy.

In order to figure out how to strengthen legitimacy of health-care decisions in a comprehensive manner, we need analytical distinctions between those being concerned by the decisions but who might be so for different kinds of reasons according to their role in the distribution of public services. The concerns for strengthening legitimacy on limit-setting decisions have traditionally been primarily addressed as an issue concerning the legitimacy conferred by citizens. Their role, however, can encompass being patients in need of services, next a kin to patients, being taxpayers or more generally, being individuals subjected to the authoritative decision-making of others. The legitimacy citizens in these roles confer on health-care decisions is of course central in a democratic system. However, in the overall picture, issues of conferring legitimacy can-and as we will argue, it should —also be ensured by people who play the particular roles of being engaged in the organization and provision of health care such as politicians, managers and health-care givers (see also Nedlund, 2012). Our aim is to shed light on this latter perspective by focusing on health-care workers in particular and their reasons for considering limit setting in publicly funded health care as legitimate. Clearly, in a democracy context, these reasons cannot be incoherent with values that constitute democracy as such. As the perspectives of citizens in general are the perspectives of those being subjected to decisions, while the perspectives of healthcare workers (considered as health-care workers) are the perspectives of those who implement the decisions, the different perspectives and their impact on the act of conferring legitimacy to a decision, should analytically be kept apart. We suggest this can be done by distinguishing between conferred legitimacy by subordinates on the one side and the health-care workers who are implementing policies on the other, and we refer to these different versions of legitimacy as subordinators' conferred legitimacy and health-care workers' conferred legitimacy.

We will start by disentangling the multi-facetted concept of legitimacy in order to identify conceptual versions that may fit with democratic decision-making concerning limit setting within publicly funded health care. Next, we discuss a moral argument and an epistemological argument that support our claimed importance of ensuring health-care workers' conferred legitimacy, and also examine how 'health-care workers' conferred legitimacy' relates to 'subordinators' conferred legitimacy'. Finally, we sketch out some conditions for facilitating health-care workers' conferred legitimacy, which we strongly recommend are attended to when limit-setting processes are designed.

\section{Political Legitimacy}

\section{Empirical and Normative Legitimacy}

Legitimacy is a complex concept and, as Suchman (1995: 572) points out, it is 'more often invoked than described' and 'more often described than defined'. Legitimacy has been described as comparable with the economist's invisible hand, where it is known as a force that holds societies together, but where we know very little about the explanations of how legitimacy is created and why it changes (Stone, 2002: 285). Another example of the messiness surrounding this concept is the notion of 'democratic legitimacy'. 'Democratic legitimacy' entails ideas of appropriate decision-making procedures, authority's right to use power and make binding decisions for the organizations in question and possibly society's confidence and trust in the fairness and suitability of their government (Dahl, 1989; Peter, 2009). However, this description is not universal, and not necessarily uncontroversial.

Roughly, legitimacy can be distinguished by two different approaches to how the idea is understood: (i) empirical $^{1}$ and (ii) normative. According to a classic definition formulated by Weber (1978), legitimacy is present when there is 'belief in legitimacy'. That is, a state or an authority is legitimate if the rules are believed to be legitimate, they are accepted or not challenged, by the subordinate subjects (i.e. citizens or demos). Legitimacy refers to a description of people's actual perceptions which simply explain that they give support to political authority, nothing else. Hence, legitimacy in this sense is primarily understood as an issue of a de facto, socially accepted political order. This definition of legitimacy is an empirical and not a normative one; it does not say anything about the appropriateness of the system or the regime in which the power is used, or the conditions that need to be satisfied for a decision to be called legitimate. Democracy is not understood to be a precondition for legitimacy. Indeed, an undemocratic regime is understood as legitimate if the subjects believe it to be so.

Beetham (1991) presents a broadened meaning of legitimacy when he argues that the justification of whether legitimacy is present should be based on socially 
accepted, normative beliefs about how the world should be organized and governed. In that way, he connects the idea of legitimacy to a call for normative justification of the conditions that is taken to constitute legitimacy. Accordingly, a political authority is not legitimate just because a citizen believes it to be so, rather the authorities' power is legitimate if (i) it is in accordance with established rules (political structures or public policies), i.e. legality; (ii) the rules are justifiable to socially accepted beliefs shared by both dominant and subordinate, i.e. justification and (iii) if there is an expressed consent by the subordinate to the particular power relationship, i.e. legitimation/consent. Normative legitimacy refers to conditions that need to be satisfied for the orders and practices of the political authorities to be considered as legitimate. In this sense, the concept of legitimacy can encompass the particular notion of 'democratic legitimacy'. Moreover, if a decision is made in a democratic order, it is an important reason why people actually accept the decision (i.e. empirically), but the democratic order is an independent argument for the specific case (i.e. normative) (Axberg, 2010). Normative legitimacy relates to both procedural and substantive aspects. The former version relates to a certain way of organizing a procedure of policymaking. The latter version relates to the acceptance of the decision's outcome and content in terms of 'correctness' (judged by whatever standard). In other words, normative legitimacy may not only encompass how or by whom a decision is decided, but also what is decided. These are not symmetric; a procedural rightfulness does not have to make the content of a decision legitimate, the outcome may conflict with certain values that are regarded as necessary for legitimacy, and vice versa; if judgements are made through another procedure than that which is regarded as legitimate, the judgement will not have a legitimate basis in that matter (Peter, 2009).

Clearly, already on a general approach, the conceptual understanding of legitimacy is complex. At this point, we leave the empirical legitimacy unelaborated behind as we try to pin down the relevant content and structure of 'legitimacy' when used to assess decision-making in publicly funded health care in coherence with democratic values. In the following, we will elaborate further on aspects related to normative approaches of legitimacy.

\section{Legitimacy and Democracy}

Legitimacy is usually placed and discussed in reference to a democratic setting. One argument is that if democratic authorization is possible, it is a necessary condition for legitimacy (Buchanan, 2002). Also Rawls (1995: 148) places legitimacy in a democratic setting by emphasizing the role of constitution where he states that 'the exercise of political power is legitimate only when it is exercised in fundamental cases in accordance with a constitution, the essentials of which all reasonable citizens, as free and equal, might reasonably be expected to endorse'. By referring to democratic legitimacy, one emphasizes that legitimacy relates to ideas of democracy, democratic values and values of a democratic decision-making process (Held, 1987; Dahl, 1989; Beetham, 1991; Cohen, 1997; Dryzek, 2010; Peter, 2009). This is a contrast to conceptions of political legitimacy that may only include attributed instrumental value to democratic decision-making (for further discussion, see Peter, 2009: 2). Theories of democracy differ in what they single out as the main features of the democratic process and the significance attached to them, e.g. representation, participation, accountability and/or deliberation. Thus, the conceptions of legitimacy may also be regarded from a normative perspective as encompassing, for example, dimensions of participation (Pateman, 1970), principle of majority (Barry, 1991), deliberation (Gutmann and Thompson, 1996; Estlund, 1997; Peter, 2009), constructive function of social learning (Peter, 2009) or discursive representation (Dryzek and Niemeyer, 2008). Thus, depending on the underlying normative ideas of democracy, the conceptions of democratic legitimacy are described and defined differently. Accordingly, dimensions of democratic legitimacy other than the three dimensions of legitimacy presented by Beetham, i.e. legality, justification and legitimation/ consent, are commonly added as morality (where the subordinates granting legitimacy must do so because they believe it is morally right to do so), freedom (they must do so freely), transparency and competence (they must do so in full awareness of what they are being asked to accept) and requirement of public authorization (where decision-makers actually can make decisions but are accountable to the public) (Dryzek, 2010). Yet, another dimension emerging from the adherents of deliberation is that the acceptance has to reflect effective participation of autonomous agents. This implies that deliberation is necessary for a democracy, and thus for legitimacy (Dryzek, 2010). Procedural aspects of democratic legitimacy relate to the decision or policies being made in accordance with a democratic order, and substantial aspects relate to the outcome of a decision not conflicting with broadly accepted values. In this article, we presume that limit setting in health is taking place within a democratic system and the concept 
of 'democratic legitimacy' will be used, since legitimacy in a democratic system is what is presupposed.

\section{Pure Proceduralism Versus Rational Proceduralism}

Legitimacy can also be distinguished between pure proceduralism and rational proceduralism (as a parallel to Rawls' distinction between pure procedural justice and rational procedural justice ${ }^{2}$ ). Roughly speaking, the differences between these two are that according to pure proceduralism the decision is legitimate if the process satisfies certain conditions. This procedure can either be determined by a majority rule, where all expressed preferences are given equal consideration, or by procedural fairness, where all those affected have an opportunity to deliberate under conditions of e.g. political equality. In rational proceduralism, a decision is legitimate if it has been generated through procedures (many times referred to as 'fair') and if it satisfies certain rationality constraints (or quality of outcomes). Hence, in the latter version, legitimacy is dependent not only on an appropriately justified decision-making process but reference is also made to procedure-independent standards of 'truth' or 'correctness' in the outcome (Peter, 2007). Also, in both of these two different versions of legitimacy, i.e. pure proceduralism and rational proceduralism, we can find the two variants of so called aggregative and deliberative models, where aggregative refers to equal consideration of all expressed preferences and where deliberative primarily concerns the opportunity people have to participate in the deliberation process (Peter, 2007). Moreover, yet another dimension can be added to pure proceduralism and rational proceduralism, the epistemic dimension, which implies that there is value to knowledge-producing in democratic decision-making. In pure epistemic proceduralism, the epistemic value derives from the contributions of the participation of those affected, which facilitates contestation of the reasoning concerning the common good, from various perspectives. It is not just a matter of equal opportunities to participate in deliberation but also a matter of adequate deliberation when gathering and analysing facts in order to shape and formulate policies (Peter, 2007). As a contrast, in rational epistemic proceduralism, where there is a presupposition of a correct outcome, the epistemic value is the truth-tracking potential of a democratic process, as representing the common good.

To sum up, limit setting in health-care is clearly value-laden, many times controversial and might even sometimes be traced to disagreement about nonnormative factual matters (as a parallel see Kappel, 2012). Pure proceduralism, because of its strong focus on the procedure as the only relevant element, falls short in a limit-setting health-care context since it can lead to bizarre outcomes, as in e.g. the case of the original Oregon list where tooth capping was ranked above appendectomy (Ham and Coulter, 2003). On the other hand, rational proceduralism seems to be relevant in that not only should those affected by a decision have the opportunity to act as autonomous citizens in a deliberating process (see Dryzek, 2010) but the quality of outcome should also be attended to. Though, 'correctness' in these situations can be argued as normatively misleading since differences in values might be treated as something that one wants to eliminate rather than accept (see Peter, 2007). Not least since, legitimacy is distinct from properties of being morally right, just or permissible and legitimacy should also remain distinct from correctness (Kappel, 2012: 7). Accordingly, we adhere to the view that legitimacy should nonetheless track correctness (cf. Kappel, 2012: 7). Hence, in our understanding of how to achieve legitimate limit-setting decisions in health, we endorse the view that conditions shaping the decision-making process also must ensure a certain standard with respect to the outcome. More precisely, we take it that the process must involve adequate collective deliberation among stakeholders representing the widest scope of relevant roles and knowledge as possible and at the same time address the possibility that multiple values as well as strong interests are involved. Conditions must be structured so as to ensure some level of non-arbitrary reasonableness in the outcome, and 'reasonableness' can be understood as the intention people who are interested in finding mutually justifiable conditions for cooperation are seeking for. (For a view according to these lines, see Daniels and Sabin, 2008; Kappel, 2012).

\section{Approaching Health-care Workers' Conferred Legitimacy}

So, how should we perceive the role and perspectives of health-care workers within this myriad of conceptualizations of legitimacy? Empirical research could reveal their actual perspectives, but here we will focus upon their normative reasons for conferring legitimacy. What gives the health-care workers justified reasons to confer legitimacy to limit-setting decisions? Do they posses some exclusive knowledge that may add to the epistemic dimension of the decision-making process? And more 
fundamentally, we must raise the question on why we should care about health-care workers' conferred legitimacy as a special case at all? Should their justified reasons for conferring legitimacy not be considered as the same as for any citizen who is observing or receiving the care in question? Should their justified reasons for conferring legitimacy be considered as coinciding with those of the authorities in considering the decisions legitimate? Or, should health-care workers' specific role as health-care givers simply count in its own right, and prompt us to carefully consider criteria that justify their particular reasons for conferring legitimacy to health-care limit setting?

In the following, we argue that consistent argumentation concerning democratic legitimacy is in fact in line with this latter perspective. As a first step, we promote a moral argument. We argue in favour of considering health-care workers as moral agents, and we consider the political consequences of this perspective when it comes to justifying health-care workers' participation in decision-making processes. As a second step, we distinguish between different kinds of limit-setting decisions and the various hats health-care workers could wear in a decision-making process. To note, here we distinguish them from elected politicians and appointed political stakeholder that might also be involved in the limit-setting process. In this article, we are interested in the health-care workers' conferred legitimacy because of their role as implementers of limit settings. Moreover, we consider the epistemological structures and tensions underlying the role of health-care givers. From these considerations, we provide what we summarize as an epistemic argument for the justified participation of health-care workers in limit-setting decision-making. As a third step, we discuss the relation between healthcare workers' and subordinators' conferred legitimacy. This discussion is embedded in what we refer to as the 'promotion of subordinators' conferred legitimacy argument'. Finally, based on these three distinct arguments, we wrap up by sketching out recommended, normative conditions for how to include health-care workers in political decision-making processes concerning limit settings in health care.

\section{A Moral Argument: Realizing the Democratic Value of Equal Regard}

A fundamental idea underlying efforts to realize democracies is the idea that people should have equal opportunities to affect political decision-making (Dahl, 1989). This idea stems from the crucial principle of moral equality, i.e. the assumptions that every human being has identical worth and should be treated accordingly. Politically, in the case of limit setting in health, this is reflected in the requirement (expectation) that decisions must be based on justified, relevant differences in what constitutes the patients' perceived 'needs' and not on personal characteristics (e.g. gender, age and ethnicity). Socially, moral equality is confirmed when mutual recognition takes place in inter-human encounters. But then the question is: what should we understand by 'mutual recognition'?

Rawls provides content to the idea of 'mutual recognition' in settings where people are involved in political deliberation. 'Mutual recognition' is at play when deliberating agents are willing 'to propose principles and standards as fair terms of cooperation and to abide by them willingly, given the assurance that others will likewise do so' (Rawls, 1993: 49). Rawls' agenda is political and focuses on justice. Scanlon provides us with a theory on 'mutual recognition' that applies in social settings in general. He stresses the idea of 'mutual recognition' in his moral theory concerning the part of morality 'having to do with our duties to other people, including such things as requirements to aid them, and prohibitions against harming, killing, coercion, and deception' (Scanlon, 1998: 6). In contrast to Rawls, Scanlon aims to clarify the normative and motivational force of judgments on right and wrong playing out in inter-human relations in general and not merely in discussion of political issues. He holds the view that ' . . . thinking about right and wrong is, at the most basic level, thinking about what could be justified to others on grounds that they, if appropriately motivated, could not reasonably reject' (Scanlon, 1998: 5). Reasonable judgments are judgments 'about the suitability of certain principles to serve as the basis of mutual recognition and accommodation' (Scanlon, 1998: 194). Scanlon has adopted the phrase 'what we owe to each other' to label the part of morality he has in mind. He explains the special authority of requirements of justifiability to others by showing that this idea is involved in our relations with each other, in aspects of life that matter to us. In this way, 'reasonableness' according to Scanlon relates both to an appropriate way of justifying a course of action as well as to the accompanying motivating reasons that emerge out of 'what we owe to each other'.

When health-care workers are implementing healthcare decisions, mutual recognition of moral equality should be realized within two different relations: 
between authoritative decision-makers and health-care workers on the one side and between health-care workers and patients on the other. At the point of encountering people with needs, health-care workers would be expected to act under the same conditions that characterize all human interaction. Provided that Scanlon is right about mutual recognition being played out in terms of required justifiability of the principles accounting for our actions, health-care workers-as everybody else-would be subject to the requirement of justifiability when acting as moral agents. If healthcare workers are unable to justify the limit-setting policy, i.e. why they deny care to the patients who stand before them, the conditions that enable them to act as moral human beings is threatened; they cannot demonstrate mutual recognition. Moreover, if healthcare workers are deprived of the opportunity of being enabled to justify their actions as reasonable towards those adversely affected by them, health-care workers worth as moral agents is undermined. In such cases, health-care workers are not recognized as moral equals to the authorities originally dictating the policy. To clarify this point according to what frames legitimate limit settings in health care, we need to specify what lies in 'having the opportunity of being enabled to justify the reasonableness of one's actions'.

In liberal, modern democracies, and due to what Rawls called 'the burden of judgment', people are expected to disagree about distributive principles that justify limit-setting decisions as right or wrong. Thus, opposing views on particular decisions would be expected. Conversely, judging a decision as 'legitimate', does not mean one approves the decision as the only right one. It means that even though one may disagree on the rightness of the principle structuring the decision in this particular setting, one does recognize that the decision is reached by a procedure one considers fair, and thus decisions are produced based on principles that are at least to be considered reasonable (ref Rawls, 1993; Daniels and Sabin, 2008). This is in accordance with the structure of procedural legitimacy described above. So, by arranging fair processes and thus giving health-care workers the opportunity of being able to justify limit setting as 'reasonable' or 'legitimate' (although they may not agree on their rightness), the decision-making authorities provide health-care workers with required conditions for acting as moral agents. And by doing so, they also confirm health-care workers as moral equals. If decision-making authorities do not offer health-care workers an opportunity to recognize justifying reasons as reasonable on the other hand, they demonstrate disrespect of health-care workers' moral status. Clearly, this would contradict a bearing value of democracy. Therefore, health-care workers should be enabled to confer legitimacy on the limit setting in their own right, parallel to the justified role citizens enjoy in conferring legitimacy to the decisions.

Allowing health-care workers to influence limitsetting deliberation in this way is also supported from another moral point of view. Health-care workers' exclusive access to the consequences for those who experience limits to health care also puts them in a position to voice concerns on behalf of vulnerable patient groups. This is of moral-political importance as these patients may not be able to raise their own voices. Thereby, they also fill the central role of 'guardians of democracy' (Lundquist, 1998). According to Lundquist, the workers in a public organization, such as the health-care staff, have the responsibility, besides being the 'servants of democracy', to be the 'guardians of democracy'. The latter implies that they are personally responsible to enhance democracy in the relation between the public and its citizens. To be a guardian implies whistle blowing if the public moral values are challenged, to make the public organization and its work transparent for the citizens, to make good decision material and to frame problematic issues in such way that a public debate is clearer for the citizens. Lundquist emphasizes, however, that the role of guardians should not prevail over the politicians' or citizens' tasks, and that the role as a guardian is a personal role. Hence, Lundquist sheds light on the moral and political responsibility of health workers to consider and protect public values. The consequences of taking this responsibility might have an impact on the shaping of both the procedural aspects as well as the substantive outcome of policy-making decision.

The political consequence of this argument in terms of the relative political influence health-care workers should have on limit-setting processes compared with other citizens or elected politicians, needs further justification. This must be discussed and justified according to health-care workers' potentially exclusive impact on the epistemological dimension of a limitsetting procedure. If they should be considered as having such exclusive impact, but are not allowed to bring it about, that would be a good reason for healthcare workers not to confer legitimacy on the decisionmaking process. In the following, we will discuss whether health-care workers possess exclusive, relevant epistemological access to a reasonable outcome according to different versions of limit setting that can be carried out. 


\section{An Epistemic Argument: Health-care Workers' Justified Contributions in Shaping Policy-Making Outcome}

To further approach the role that health-care workers could and should play according to an epistemic dimension of legitimate policy-making, we need to make a short demi-tour. For analytic purposes, we provide a rough categorization of different versions of limit setting in health care.

\section{The Structures of Making Limit-Setting Decisions}

Firstly, we distinguish between the more untargeted limit-setting decisions of health care, concerning the distribution of human and material resources, as well as budget constraints placed on organized activity. The aim of these decisions is not targeted limit setting of clinical care as such, although some limit setting is nevertheless the consequence of the decisions. Such decisions can be carried out by the political health authorities (at the macro level), and within the management of organized, medical institutions (at the meso level). Secondly, more targeted limit setting is carried out when explicit decisions are made on what preventive, curative or rehabilitating interventions should not be made available, either concerning what the health-care package should include or in the form of denial or deliberate delay of care within the health-care package (Klein, 2010). These decisions can be settled by political authorities at the macro level, by the management of medical institutions at the meso level and also by clinicians providing the care at the micro level. Thirdly, implicit limitsetting decisions take place when biased focus on certain prioritized interventions leaves other, potentially beneficial treatment opportunities delayed or neglected (e.g. by application of clinical guidelines or established practices pointing out some standard treatment). Implicit limit setting is basically carried out at the clinical, micro level.

Health-care workers might actively take part in and influence any of these limit-setting decisions. However, in order to identify the kind of influence they are justified in imposing, we need to distinguish carefully between the hats they are wearing - and the kind of impact they are entitled to exercise at that time-from a democratic point of view. Empirically, health-care distribution is likely to be considered a mixture of various models of administration (Rothstein, 2008; Nedlund, 2012). Normatively, justified organization of limit setting basically concerns transparency, accountability and justifiability (e.g. Daniels and Sabin, 2008) as well as impartiality (Rothstein, 2008). It can be added that within a public health-care system, limit setting is incompatible with democracy unless the decisions are clearly anchored within responsible political authorities. This means that health-care workers in the role as health-care workers cannot rightfully take discretionary control over the moral-political distributive issue of what care should be rationed, be it at macro, meso and micro level, and at the same time realize democratic decision-making. They may, however, participate in limit-setting processes and influence the outcome through deliberation, but then the lines between acting as health-care professionals/experts and acting as citizens or politicians must be carefully drawn in order to sustain democracy.

In the following, we will isolate the particular assets of health-care workers that justify_as well as specifytheir participation as experts in a democratic limit-setting process in line with the distinct roles assigned to politicians and citizens.

\section{Epistemic Challenges in Reaching Reasonable Limit Setting in Health Care}

It has been argued that what can be justified as fair decision-making on a population level according to aggregated data, does not necessarily come out as equally legitimate at the individual level where particular, individual characteristics are taken into account (Bærøe, 2008, 2009). Limit setting in health care can be justified according to the selected set of characteristics of a patient group or an intervention. Such characteristics can correspond to acknowledged moral merits qualifying for special attention (e.g. severity), or descriptions enabling quantification and comparison across populations or interventions (e.g. qualityadjusted life years metrics). At the clinical level, in face-to-face encounters with individuals, patients present themselves with a much richer set of characteristics and concerns, which are potentially relevant for entitlement to health care, i.e. provide more reasons subject to what Scanlon conceptualizes as 'what we owe to each other'. Health-care workers are in a position to identify this broader scope of reasons. This means they can feed experiences with patients and their health-related challenges into the policymaking process ex ante limit setting, and when limit setting is being implemented, they 
can identify previously neglected consequences of the limit-setting decisions, and thereby potential reasons calling for a reconsideration of the decision ex post implementation, i.e. according evaluation. In this respect, health-care workers can have an important, irreplaceable role to play in policymaking processes aiming for legitimate decisions.

Moreover, health-care workers are of course also trained in understanding the relation between symptoms and conditions and between identified conditions and apt interventions, as well as in assessing the scientific evidence for beneficial treatment. In all these respects, their specific competence becomes highly relevant from an epistemological point of view. From a democratic perspective, however, the legitimacy brought into the decision-making process by the normative, personal judgments of health-care workers concerning the relative importance of needs compared with other needs (and underlying moral principles for distribution), should be considered separately from their clinical experiences and scientific knowledge. This claim needs to be discussed further.

In order to promote democratic legitimacy, institutionalized decision-making design cannot assign special weight to some participants' value judgments without some proper justification for doing so. It can also be argued that in a democratic setting, and in general, there is initially no reason to appreciate and trust health-care workers' personally preferred moral principles for distribution in health, more than the preferences of any other citizens. There is nothing in medical and health-related education that supports health-care workers with superior normative judgment as such. Their normative judgments are subjective, as they are for anyone else. At the same time we do allow, and are to some extent forced to allow, health-care workers discretionary power to individualize appropriate health care. To carry out individualized health care in institutions at 'street-level' is intrinsically based on health-care workers' normative assumptions about 'needs' and traceable, distributive principles regarding 'who should get what when' (Bærøe, 2011). The lack of democratic control over the normative premises for the distribution at the street-level implementation of health care, is appropriately referred to as 'the black hole of democracy' (Eriksen, 2001; Rothstein, 2010). Efforts to gain some kind of democratic control over this last and crucial step of distribution, represents a challenge indeed. It has been argued that in order for the 'street-level judgments' of health-care workers to be sufficiently epistemologically justified to be characterized as legitimate in a democratic setting, the discretion exercised by this work force will have to comply with a comprehensive framework of normative conditions, requiring self-reflection and public testing of their points of view (Bærøe, 2009).

When it comes to participation in explicitly designed limit-setting processes, putting emphasis on health-care workers' participation and consideration is basically justified on the exclusive access to clinical and social consequences for those who are experiencing limits to health care. This knowledge is important for an adequate description of what is actually at stake, and advance the articulation of the normative trade-offs involved in a limit-setting process. In this respect, health-care workers should be assigned a crucial role in deliberation concerning limit setting during ex ante and during ex post implementation, which in turn would then give them one reason to confer legitimacy on the decision.

\section{An Argument for How Health-care Workers' Conferred Legitimacy Supports Subordinators' Conferred Legitimacy:}

In this section, we will argue that health-care workers' conferred legitimacy might provide even further reasons for subordinators to confer legitimacy to the limit-setting decision along two axes. First, the public's firsthand evaluation of the limit-setting outcome of a macro level policymaking process will take place in a clinical, micro-level setting when individuals are experiencing a need for a potentially beneficial treatment that is decided to go unmet. If health-care workers have been given an opportunity to assess the limit setting as reasonable through an adequately designed process, they can play an important role in mediating the justifiability of such decisions towards those being affected by them. In this respect, health-care workers' conferred legitimacy can have an intrinsic value for subordinators' approval of reasonableness and subsequently, their conferred legitimacy. Without health-care workers approving of the outcome of the policy-making process accordingly, the risk increases that the macro level limit-setting decisions might be counter-acted at the point of care (see e.g. Peacock et al., 2009).

Second, health-care workers is placed so as to make use of their exclusive access to knowledge of micro-level contexts in policymaking and thus to add relevant information about context-dependent consequences for individuals (both ex ante and ex post implementation) 
to decisions otherwise merely made on the basis of 'nonindividual', aggregated, context-independent factors. In this sense, subordinators have reasons to believe that health-care workers' possibility to influence and shape the final limit-setting decision implies a better quality of outcome in terms of reasonableness. A policymaking process that allows for health workers' micro level knowledge to impact on the final policy-decision provides health-care workers with better reasons to confer legitimacy than if this was not the case. Hence, ensuring legitimation of health-care workers in this epistemic aspect also provides subordinators with more justified reasons to confer legitimacy to the limit-setting decisions as well.

Third, health-care workers' conferred legitimacy can also be related to another form of epistemic value where health-care workers have the possibility to participate and confer legitimacy and also bringing together various perspectives is highlighted. A policymaking structure, having deliberation without the necessity of coming to a final agreement/consensus, can have the value of revealing that many limit-setting decisions are not always rational epistemic. ${ }^{3}$ What this also promotes is that in a democracy people can disagree, have the right to do so and are even normatively encouraged to do so. If this is reflected and acknowledged within the health-care institution, then it might be easier for citizens to also regard this matter both in the sense that the various experts can have different views on the specific issue, and in the more general sense that various perspectives, including their own, are valuable when there are disagreement and no 'correct' outcomes to hand.

\section{Sketching Out: Normative Conditions for Health-care Workers' Conferred Legitimacy}

Based on the discussion above, we can sum up three argumentatively distinct sources of the importance of ensuring health-care workers' conferring legitimacy within the health-care limit-setting processes. Firstly, organizing limit setting so that health-care workers are justified in conferring legitimacy is needed in order to confirm health-care workers as morally equal to any other human beings, including those who represent the authorities and the patient they are helping. It was argued that mutual recognition in inter-human relations presumes the ability and motivation to actually justify limit setting as legitimate at the point of denying patients particular health care. If policymaking processes do not enable health-care workers to justify limit-setting decisions as legitimate towards the patient, they are deprived of the opportunity to act as moral agents when implementing the limit setting. Thus, they are not treated as moral equal by the authorities, and neither are the patients as a consequence of not being provided adequate justification for not receiving potentially beneficial care. This was the moral argument for the concern over legitimacy. Secondly, we launched an epistemic argument: to bring in and explicitly draw upon health-care workers' experiences and scientific knowledge in the limit-setting process, i.e. their exclusive epistemological access to the consequences of withholding treatment, support the aim of arranging legitimate limit setting under adequately justified epistemic conditions. Thirdly, the different arguments provided for the theoretical impact arranging for health-care workers' conferring legitimacy have on subordinators extended reasons for conferring legitimacy add even more reasons to be concerned about healthcare workers accepting limit setting as legitimate.

If we now return to the distinctions also made above between different versions of limit setting, we can spell out how these should be arranged with respect to the participation of health-care workers, in order to give them reasons to confer legitimacy to the decisions.

It can be argued that health-care workers should have a say with respect to untargeted limit-setting decisions of health care, concerning the distribution of human and material resources, as well as budget constraints on organized activity. As long as limit setting is the consequence of such decisions, health-care workers should be consulted on the anticipated consequences for patients indirectly affected by the decisions. Without this opportunity to influence these decisions with their specific competence, health-care workers do have at least one reason not to consider the decision legitimate. Further, when explicit decisions are made on what preventive, curative or rehabilitating interventions should or should not be made available, health-care workers should be engaged in deliberations and evaluation by informing on the anticipated and realized impact of the proposed limit setting. Again, if they are not represented in these parts of the policymaking process, they are not justified in conferring legitimacy to the policy decision. Finally, in the case of implicit limit-setting decisions being made, when biased focus on certain prioritized interventions leaves other potentially beneficial treatment opportunities delayed or neglected, the health-care system must be organized so as to support and channel relevant information and protests of health-care workers. In short, if health-care workers 
are denied the opportunity to act as moral agents and as 'guardians of democracy' in relation to limit-setting policies, they do not have sufficient reasons to confer legitimacy on the limit setting.

\section{Conclusion}

The concept of legitimacy is often used in the context of setting limits in health care, but rarely described what is actually meant by its use. In this article, we have shed light on the role of health-care workers in limit setting by approaching reasons for implementers of health care to confer legitimacy. Supported by three different arguments, the moral argument, the epistemic argument and the promotion of external legitimacy argument, we have identified different ways health-care workers are justified in affecting limit-setting policies in health with respect to different versions of limit setting. We have shown that designing for health-care workers participation in limit-setting processes support health-care workers with substantive reasons to confer legitimacy and that this, in turn, also provides valuable reasons for subordinators, i.e. citizens, to confer legitimacy to the policies. Thereby, what is traditionally perceived as democratic legitimacy, is protected. In short, healthcare workers have an important role to play as both moral and political agents in limit setting. By designing for limit-setting decision-making accordingly, healthcare workers, as well as citizens, are more justified in conferring democratic legitimacy to health care limitsetting decisions than if these concerns were not addressed.

\section{Funding}

This work was supported by our respective employing institutions, i.e. the National Centre for Setting Priorities in Health Care at Linköping University and Department of Global Public Health and Primary Care at the University of Bergen.

\section{Conflict of Interest}

None declared.

\section{Notes}

1. Sometimes also referred to as 'social legitimacy' (see e.g. Føllesdal, 2004).

2. One difference between legitimacy and justice is that legitimacy is weaker than justice (see Rawls, 1995:
175). This can be described, as Rawls explains, in that 'citizens recognize the familiar distinction between accepting as (sufficiently) just and legitimate a constitution with its procedures for fair elections and legislative majorities, and accepting as legitimate (even when not just) a particular statute or a decision in a particular matter of policy' (Rawls, 1995: 148).

3. Peter (2009) calls this 'epistemic fairness', which relates to "people's opportunities to contribute to the constructive function of deliberative democratic decision-making." (Peter, 2009: 36)

\section{References}

Axberg, M. (2010). Fyra Länkar till Frågan om EU:s Legitimitet. Statsvetenskaplig tidskrift, 102, 289-300.

Bærøe, K. (2008). Priority Setting in Health Care: On the Relation Between Reasonable Choices on the Micro-Level and the Macro-Level. Theoretical Medicine and Bioethics, 29, 87-102.

Bærøe, K. (2009). Priority Setting in Health Care: A Framework for Reasonable Clinical Judgments. Journal of Medical Ethics, 35, 488-496.

Bærøe, K. (2011). Mellom samfunnsstrukturer og profesjon: om avgrensning, kultivering og premisser for adekvat skjønnsutøvelse i legerollen. [In Between Structures of Society and Profession: On Delimitation, Cultivation and Premises for Adequately Exercising Judgment in the Role as Physician.]. Etikk i Praksis - Nordic Journal in Applied Ethics, 2, 23-44.

Barry, B. (1991). Essays in Political Theory. Democracy and Power, Vol. 1. Oxford: Clarendon.

Beetham, D. (1991). The Legitimation of Power. Basingstoke: Macmillan.

Buchanan, A. (2002). Political Legitimacy and Democracy. Ethics, 112, 689-719.

Carlsen, B. and Norheim, O. F. (2005). Saying No is No Easy Matter: A Qualitative Study of Competing Concerns in Rationing Decisions in General Practice. BMC Health Services Research, 5,70 .

Cohen, J. (1997). Deliberation and Democratic Legitimacy. In Bohman, J. and Rehg, W. (eds), Deliberative Democracy: Essays on Reason and Politics. Cambridge, MA: MIT Press.

Dahl, R. A. (1989). Democracy and Its Critics. New Haven: Yale University Press. 
Daniels, N. and Sabin, J. E. (2008). Setting Limits Fairly: Learning to Share Resources of Health. New York: Oxford University Press.

Dryzek, J. S. (2010). Foundations and Frontiers of Deliberative Governance. Oxford: Oxford University Press.

Dryzek, J. S. and Niemeyer, S. (2008). Discursive Representation. American Political Science Review, 102, 481-493.

Eriksen, E. O. (2001). Demokratiets Sorte Hull - Om Spenningen Mellom fag og Politikk $i$ Velferdsstaten. Oslo: Abstrakt Forlag.

Estlund, D. (1997). Beyond Fairness and Delibartion: The Epistemic Dimentiosn of Democratic Authority'. In Bohman, J. and Rehg, W. (eds), Deliberative Democracy: Essays on Reason and Politics. Cambridge, MA: MIT Press.

Føllesdal, A. (2004). Legitimacy Theories of the European Union, ARENA Working Papers. 04/15.

Gutmann, A. and Thompson, D. F. (1996). Democracy and Disagreement: [Why Moral Conflict Cannot be Avoided in Politics, and What Should be Done About it]. Cambridge: Belknap Press.

Ham, C. and Coulter, A. (2003). International Experience of Rationing. In Ham, C. and Robert, G. B. (eds), Reasonable Rationing: International Experience of Priority Setting in Health. Philadelphia, PA: Open University, pp. 4-15.

Held, D. (1987). Models of Democracy. Cambridge: Polity in Association with Blackwell.

Kappel, K. (2012). Factual Disagreement and Political Legitimacy, available from: http://www.academia. edu/2592903/Factual_Disagreement_and_Political_ Legitimacy [accessed 21 May 2014].

Klein, R. (2010). Rationing in the Fiscal Ice Age. Health Economics Policy and Law, 5, 389-396.

Lasswell, H. D. (1958). Politics: Who Gets What, When, and How. New York: Meridian Books.

Lundquist, L. (1998). Demokratins Väktare: Ämbetsmännen och Vårt Offentliga Etos. Lund: Studentlitteratur.

Nedlund, A. C. (2012). Designing for Legitimacy: Policy Work and the Art of Juggling When Setting Limits in Health Care. Diss, Linköping: Linköpings universitet.

Pateman, C. (1970). Participation and Democratic Theory. Cambridge: Cambridge University Press.

Peacock, S., Mitton, C., Bate, A., McCoy, B. and Donaldson, C. (2009). Overcoming Barriers to Priority Setting Using Interdisciplinary Methods. Health Policy, 92, 124-132.

Peter, F. (2007). Democratic Legitimacy and Proceduralist social Epistemology. Politics, Philosophy \& Economics, 6, 329-353.

Peter, F. (2009). Democratic Legitimacy. New York: Routledge.

Rawls, J. (1993). Political Liberalism. New York: Columbia University Press.

Rawls, J. (1995). Political Liberalism: Reply to Habermas'. Journal of Philosophy, 92, 132-180.

Rothstein, B. (2008). Political Legitimacy and the Welfare State: Five Basic Models, QoG Working Paper Series, 2008, 9. Gothenburg: University of Gothenburg.

Rothstein, B. (2010). Vad bör Staten göra?: Om Välfärdsstatens Moraliska och Politiska Logik. Stockholm: SNS förlag.

Scanlon, T. M. (1998). What We Owe to Each Other. Cambridge, MA: Belknap Press of Harvard University Press, 1998.

Schwartz, L. (2002). Is There an Advocate in the House? The Role of Health care Professionals in Patient advocacy. Journal of Medical Ethics, 28, 37-40.

Suchman, M. C. (1995). Managing LegitimacyStrategic and Institutional Approaches. Academy of Management Review, 20, 571-610.

Stone, D. A. (2002). Policy Paradox: The Art of Political Decision Making. New York: Norton.

Weber, M. (1978). Economy and Society: An Outline of Interpretive Sociology, Vol. 1. Berkeley: University of California Press.

Weinstein, M. C. (2001). Should Physicians be Gatekeepers of Medical Resources?' Journal of Medical Ethics, 27, 268-274. 